\section{El río Grande y el corredor interoceánico de la región de tránsito panameña, 1500-1914}

\author{
The Río Grande River and the Interoceanic \\ Corridor in Panama's Transit Region, \\ 1500-1914
}

\begin{abstract}
RESUMEN
La historia ambiental del río Grande, un río panameño que desembocaba en el Pacífico y cuyo valle fue devastado con la construcción del Canal de Panamá, ofrece un caso presago de un río latinoamericano sujeto a una fractura hidrometabólica, y de una cuenca crucial en la historia ambiental de la región de tránsito de Panamá. Este trabajo reconstruirá la trayectoria del río a través de una narrativa basada en el enfoque realista de la historia ambiental, especialmente en sus conceptos de metabolismo social y fractura metabólica, como una forma de rastrear las raíces de las estructuras ambientales actuales de Panamá. Debido a la extensión del territorio de la República de Panamá, la transformación de la cuenca estuvo determinada por la economía política nacional, a varias escalas y a través de una longue durée delimitada por el transitismo como paradigma dominante entre los tomadores de decisiones.
\end{abstract}

PALABRAS ClaVE: Ríos, Canal de Panamá, Historia ambiental, Río Chagres, Transitismo.

\section{ABSTRACT}

The environmental history of the río Grande, a Panamanian river which drained into the Pacific and whose valley was devastated by the construction of the Panama Canal across the isthmus, offers an early case of a Latin American river subject to a hydro-metabolic fracture, and of a key riverscape in the environmental history of Panama's transit region. This paper will reconstruct the trajectory of the river through a narrative based on the realist approach to environmental history, especially its concepts of social metabolism and the metabolic rift, as a way to trace the roots of Panama's current environmental structures. Due to the size of the territory of the Republic of Panama, the watershed's transformation was determined by national political economy, at various scales and across a longue durée delimited by transitismo as the dominant paradigm among decision makers.

KEYWORDS: Rivers, Panama Canal, Environmental history, Chagres River, Transitism. 


\section{O Río Grande e o corredor interoceânico da} região de trânsito do Panamá, 1500-1914

\section{RESUMO}

A história do Rio Grande, um rio panamenho que deságua no Pacífico e cujo vale foi devastado com a construção do Canal do Panamá, oferece um caso pré-agitado de um rio latinoamericano sujeito a extrativismo e de uma bacia crucial na história ambiental da região de trânsito do Panamá. 0 caminho do rio será reconstruído a partir de uma narrativa apoiada na perspectiva explicativo-realista da história ambiental, especialmente os conceitos de metabolismo social como estímulo e a lacuna metabólica como fator explicativo das paisagens que produzem a atual crise. Devido ao estreito território da atual República do Panamá e à organização de sua principal atividade econômica, a transformação do Rio Grande foi determinada pela ecologia política nacional, em várias escalas e ao longo de um longo período delimitado pela validade do transitismo como paradigma. elites atuais de tomada de decisão.

PALAVRAS-CHAVE: Rios, Canal do Panamá, História ambiental, Rio Chagres, Transitismo.

\section{Le Río Grande et le couloir interocéanique de la région de transit panaméenne,1500-1974}

\section{RÉSUMÉ}

L'histoire du Rio Grande, un fleuve panaméen qui s'est vidé dans le Pacifique et dont la vallée a été dévastée par la construction du canal de Panama, offre un cas présagénaire d'un fleuve latino-américain très tôt sujet à l'extractivisme, et d'un bassin crucial dans l'histoire environnement de la région de transit du Panama. Le chemin de la rivière sera reconstruit à partir d'un récit soutenu par la perspective explicative et réaliste de l'histoire de l'environnement, en particulier les concepts de métabolisme social comme éperon et de déficit métabolique comme facteur explicatif des paysages qui produisent la crise actuelle. Du fait du territoire étroit de l'actuelle République du Panama et de l'organisation de sa principale activité économique, la transformation du Rio Grande a été déterminée par l'écologie politique nationale, à différentes échelles et le long d'une longue durée délimitée par la validité du transitisme comme paradigme élites décisionnelles actuelles.

MOTS CLÉS: Rivières, Canal de Panama, Histoire environnementale, Rivière Chagres, Transit

\section{Il Río Grande e il corridoio interoceanico dela regione di transito panamense, 1500-1914}

\section{SOMMARIO}

La storia del Rio Grande, un fiume panamense che si è svuotato nel Pacifico e la cui valle è stata devastata dalla costruzione del Canale di Panama, offre un caso presago di un fiume latinoamericano presto soggetto a estrattivismo e di un bacino cruciale nella storia ambientale della regione di transito di Panama. Il percorso del fiume sarà ricostruito da una narrazione supportata dalla prospettiva esplicativarealistica della storia ambientale, in particolare i concetti di metabolismo sociale come stimolo e gap metabolico come fattore esplicativo dei paesaggi che producono l'attuale crisi. A causa dello stretto territorio dell'attuale Repubblica di Panama e dell'organizzazione della sua principale attività economica, la trasformazione del Rio Grande è stata determinata dall'ecologia politica nazionale, su varie scale e lungo una lunga vita delimitata dalla validità del transito come paradigma élite decisionali attuali.

PAROLE CHIAVE: Fiumi, Canale di Panama, Storia ambientale, Fiume Chagres, Transito 


\section{Introducción}

El espacio que hoy ocupa el Canal de Panamá es la franja de tierra más angosta del continente, con elevaciones que no rebasan los 150 metros. Dentro del régimen climático de los últimos 500 años, estuvo protegido de huracanes, y el área goza de una falta de volcanes y terremotos además de una prolongada época seca en el Pacífico. Diversos grupos humanos aprovecharon varios puentes interoceánicos creados por la orientación de los ríos y la ubicación de sus cabeceras. En la vertiente del Caribe y sobre todo en la del Pacífico, estos ríos corrían desde su cabecera en la cordillera central hasta su respectivo océano de forma casi lineal. Bajas alturas en macizos particulares y cabeceras favorables en ambos lados de estos crearon la posibilidad de una multiplicidad de corredores que cruzaran el parteaguas continental, pero esta explotación pluralista de la interoceanidad sufrió un cambio radical durante la Conquista del istmo en el siglo XVI ${ }^{1}$. La ruta que aprovechaba la proximidad de las cabeceras de los ríos Chagres y el Grande pasó a convertirse en un eje de asentamientos con la llegada de Vasco Nuñez de Balboa, aunado al saqueo de los recursos del Nuevo Mundo por parte de Europa. La continuidad entre el modelo de economía implantado por los españoles y el actual queda reflejada en el uso de la tierra con fines ganaderos de la gran parte de la sabana del Pacífico, además de la fijación del corredor interoceánico en su fase hidráulica, como se desarrollará en este trabajo.

El giro historiográfico que ha revitalizado la temática del Canal de Panamá ha desacreditado la interpretación triunfalista que predominó en la literatura en inglés desde principios del siglo pasado. La interpretación vigente rechaza las narrativas de conquista del hombre anglo sobre la naturaleza, y complica la relación del Canal con la república y hasta el proyecto imperial norteamericano. El nuevo enfoque propone estudiar la emergencia de nuevas ecologías formadas posteriormente a la construcción de la vía acuática. La construcción del problema hídrico en Panamá, el cual trasciende los límites de las cuencas del canal y la región central del istmo, tiene sus orígenes en la cultura del agua impuesta por tecnócratas estadounidenses, y en procesos de aún más larga duración que acarrea Panamá del periodo colonial. Más que la deforestación a gran escala o la degradación de recursos marino costeros, las consecuencias estructurales más consecuentes

1. Castro Herrera, 2013. del corredor fluvio-terrestre español, alimentado por el trabajo de esclavos africanos y mulas nicaragüenses, fue el arraigamiento de patrones espaciales de población, y la rearticulación del río Grande al río Chagres. Esta ruta fue utilizada por los pueblos originarios, pero la organización del territorio posterior a la Conquista la estableció como la ruta transístmica oficial. La monopolización de una ruta única, y la prohibición del uso de corredores interoceánicos alternativos, siempre fue una precondición del llamado transitismo panameño.

El presente artículo busca esbozar la relación entre el desaparecido y olvidado río Grande y el corredor interoceánico, principal articulador de la actividad productiva en la histórica región de tránsito del istmo de Panamá. El corredor interoceánico panameño ha cumplido una función geográfica articuladora de proyectos territoriales por potencias remotas por cinco siglos, y finalmente incorporado a un estado soberano en 1999 con la transferencia del Canal. Sin embargo, el caso de estudio del desaparecido río Grande ofrece luces acerca de las continuidades y rupturas de la modernidad en el istmo, y reivindica el concepto de transitismo como factor central en la historia ambiental panameña. Las transformaciones de la cuenca del río Grande serán examinadas rastreando cambios en el uso del recurso geográfico del istmo. Este enfoque nos permite extrapolar como los humanos han valorizado y apropiado el mundo natural en la región más estratégica y densamente poblada de Panamá.

Desde tiempos pre-Colombinos, la estructura natural del medio biogeofísico del istmo de Panamá, junto con la organización territorial de este espacio, han sido determinantes en la formación de una cultura de la naturaleza. Cacicazgos indígenas posiblemente explotaron los espacios donde originaban conjuntos de ríos cuyas cabeceras se comunicaban fácilmente entre sí, ubicados en las dos diferentes vertientes oceánicas que caracterizan a Centro América ${ }^{2}$. Al organizar su producción de acuerdo a los diferentes pisos ecológicos que tipifican diferentes partes de las cuencas de los ríos del istmo-y adaptarse bosques tropicales húmedos y secos, sabanas, y varios tipos de humedales- estos pueblos aprovecharon los diversos ecosistemas de los ríos, mayormente de orientación vertical de Norte a Sur. El río Grande, que desembocaba en el Pacifico istmeño al occidente de la actual Ciudad de Panamá, era uno de estos ríos,

\footnotetext{
2. En el Mapa 1 se muestra algunas posibles rutas utilizadas para comunicar los ecosistemas de ambas vertientes aprovechándose de diversas facilidades geográficas y topográficas.
} 
Mapa 1. Posibles Corredores Transístmicos Pre-Hispánicos. Se muestra el corredor del río Grande, drenando hacía el Pacífico, y el río Chagres, drenando hacia el norte, circulado

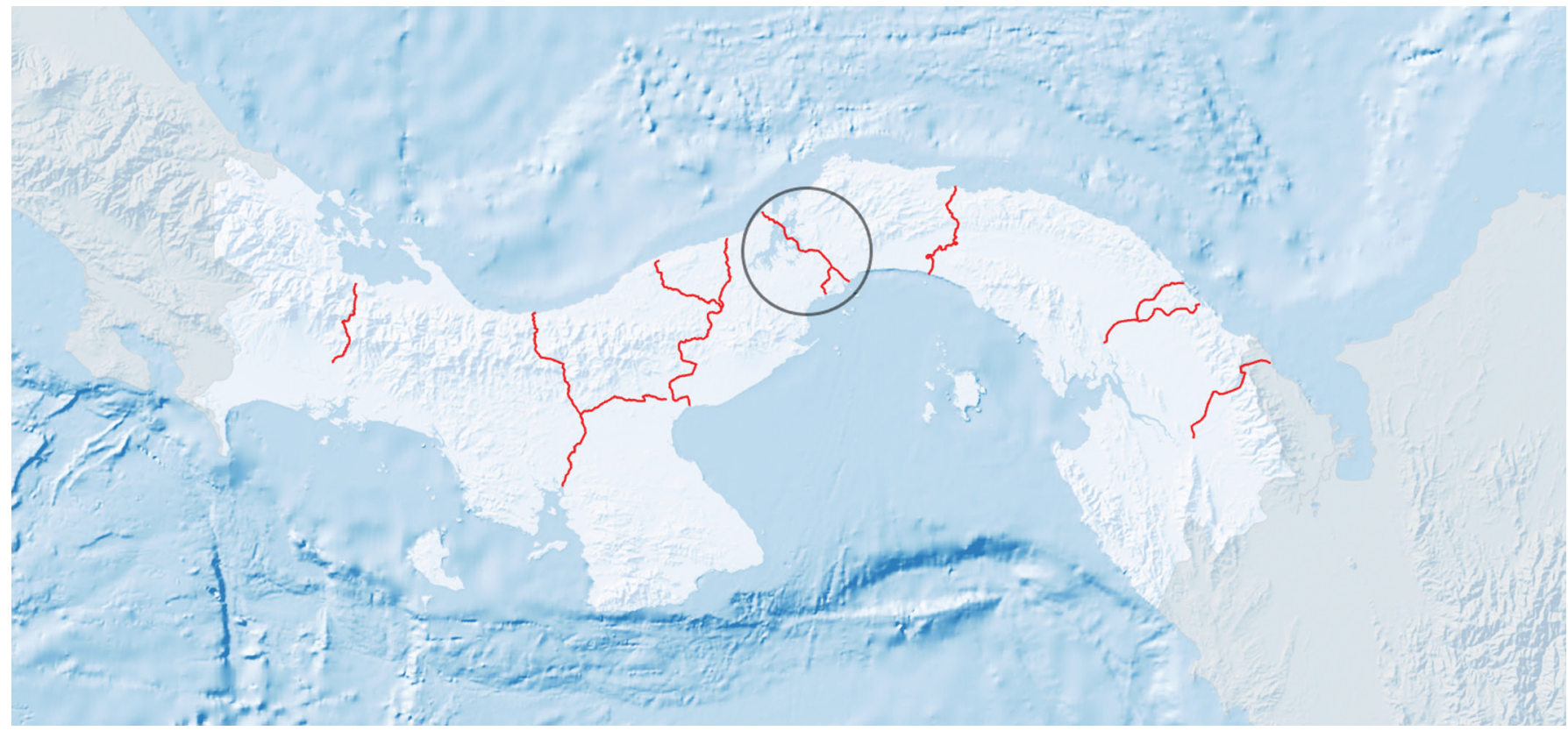

Fuente: Cortesía de ESRI Panamá y Guillermo Castro Herrera.

que formaba una mancuerna fluvial con una parte del curso del famoso río Chagres en la vertiente Caribe ${ }^{3}$. Sin embargo, con la invasión de América por parte de conquistadores europeos, estos monopolizaron el tránsito entre los mares y lo concentraron en este corredor, al cual llamaremos el corredor interoceánico. Esta organización del tránsito, la cual académicos han denominado "transitismo", conforma una estructura de larga duración en la historia del istmo de Panamá. Las estructuras del transitismo, el concepto sociohistórico que fundamenta esta narrativa, no toman forma sino a partir del siglo XVI. De este modo, el control histórico de la actividad de tránsito por una elite cambiante- ya sea compuesta de españoles, capitalistas norteamericanos, o luego tecnócratas al servicio del gobierno federal de EE.UU.- condicionó la explotación de los recursos ambientales. El río Grande ofrece un ejemplo simbólico y exagerado de este proceso que deja secuelas hasta nuestros días.

\footnotetext{
3. El Mapa 2 ilustra como las orientaciones de los dos ríos se complementaban, aunque discurriesen por diferentes vertientes y drenasen en distintos mares. Este diagrama omite el resto de los ríos del área, incluyendo los afluentes del Chagres y el Grande, para mostrar la relación entre estos dos ríos.
}

\section{El corredor interoceánico transitista}

Los diseños del imperio español para el istmo condicionaron la inserción, bastante temprana, del territorio que hoy conocemos como Panamá al sistema-mundo. Con la acumulación originaria del siglo XVI, el metabolismo social de la ecología-mundo se aceleró, alterando el régimen de utilización de recursos asociado con el corredor interoceánico constituido por los ríos Chagres y Grande.

El tráfico de personas y lingotes de plata procedentes del mundo incaico a través del istmo hacia Europa cumpliría una función importante en el orden social del istmo. Aunque generando una huella ecológica menor a la que tendrían las futuras formas del corredor interoceánico, las rutas fluviales, mixtas y terrestres que controlaría el Imperio Español tendrían un impacto trascendental en la conformación de una lógica territorial en el istmo. Los paisajes transitistas, principalmente el camino de piedras del Camino de Cruces (marcado en rojo con su embarcadero en el río Chagres Venta de Cruces en el Mapa 3), articularon diferentes actividades productivas a lo largo de la vertiente del Pacífico, como la ganadería y las recuas de mulas. Una nueva elite se beneficiaría desproporcionalmente de este corredor, a través de la apropiación del excedente del sector servicio y los sectores primarios minoritarios. Esto llevó al territorio que hoy conforma Panamá a exhibir una for- 
Mapa 2. Diagrama Mostrando el Encadenamiento entre los Principales Ríos (sin sus subcuencas) Navegables de la Región Centro-Oriental del Istmo de Panamá.

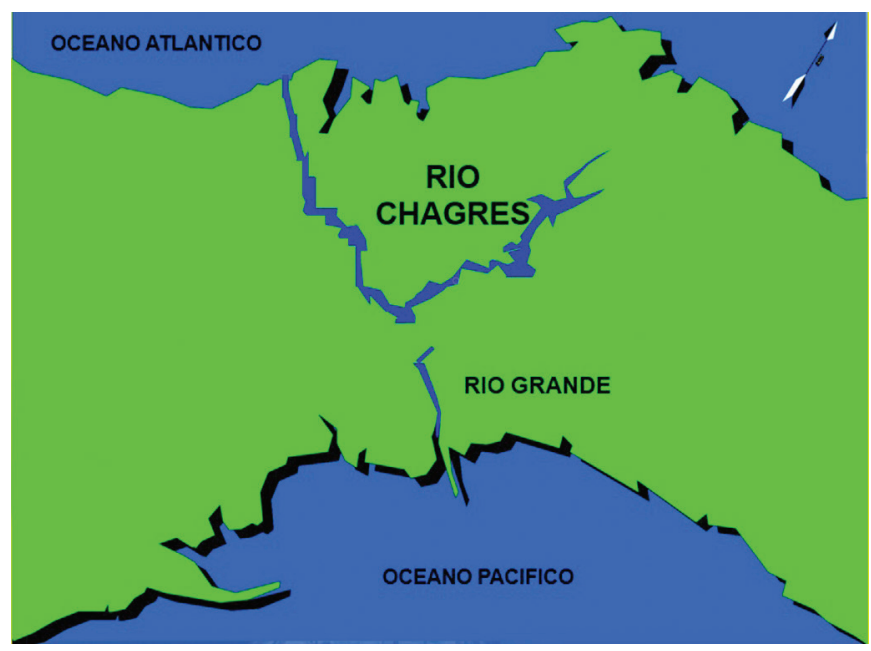

Fuente: Oscar Bazán, “Ampliación del Canal de Panamá y su Impacto en los Puertos Colombianos." División de Mercadeo del Canal de Panamá. www. pancanal.com

ma de desarrollo combinado y desigual. Con el paso del tiempo, este desarrollo generó un creciente deterioro ambiental explicable en gran parte desde las estructuras heredadas del periodo colonial ${ }^{4}$.

Luego de la destrucción del hoy famoso Panamá Viejo en 1671, en vísperas de la invasión liderada por Henry Morgan, la ciudad de Panamá, la terminal sur de las rutas coloniales, fue reubicada al área del cerro Ancón, la elevación de 200 metros que dominaba el paisaje de la cuenca baja y la boca del río Grande. Alfredo Castillero Calvo menciona que el sitio fue llamado "Ancón" debido a la existencia de dos ancones, el término castellano para los puertos fondeables. Uno de estos era la desembocadura del río Grande, donde se encontraba el Puerto de La Boca ${ }^{5}$, que quedó así vinculada al sistema urbano en transición. El régimen de ferias, articulado al sistema de flotas y galeones, constituía el principal vínculo del istmo al sistema-mundo, y condicionó las decisiones de organización territorial que se tomaban en la colonia. El deseo de evitar contacto con cimarrones rebeldes y prevenir el contrabando, por ejemplo, llevó al régimen español a establecer su exclusividad en la utilización de

\footnotetext{
4. Castro Herrera, 2013.

5. El Puerto de la Boca es el mismo al que el Presidente de los Estados Unidos, Grover Cleveland, Ilamó Ancón. Además, es antecesor del actual Puerto de Balboa. Lasso realiza una lectura desde la historia espacial de las diferentes iteraciones del puerto en función de las cambiantes etapas del corredor interoceánico. Solo con la llegada de la Comisión de EE.UU. se desvinculó la ciudad de Panamá de su puerto internacional. Lasso, 2019, 21-50.
}

Mapa 3. - Rutas terrestre y mixta a través del Istmo de Panamá en el siglo XVI tardío, y los ríos del área

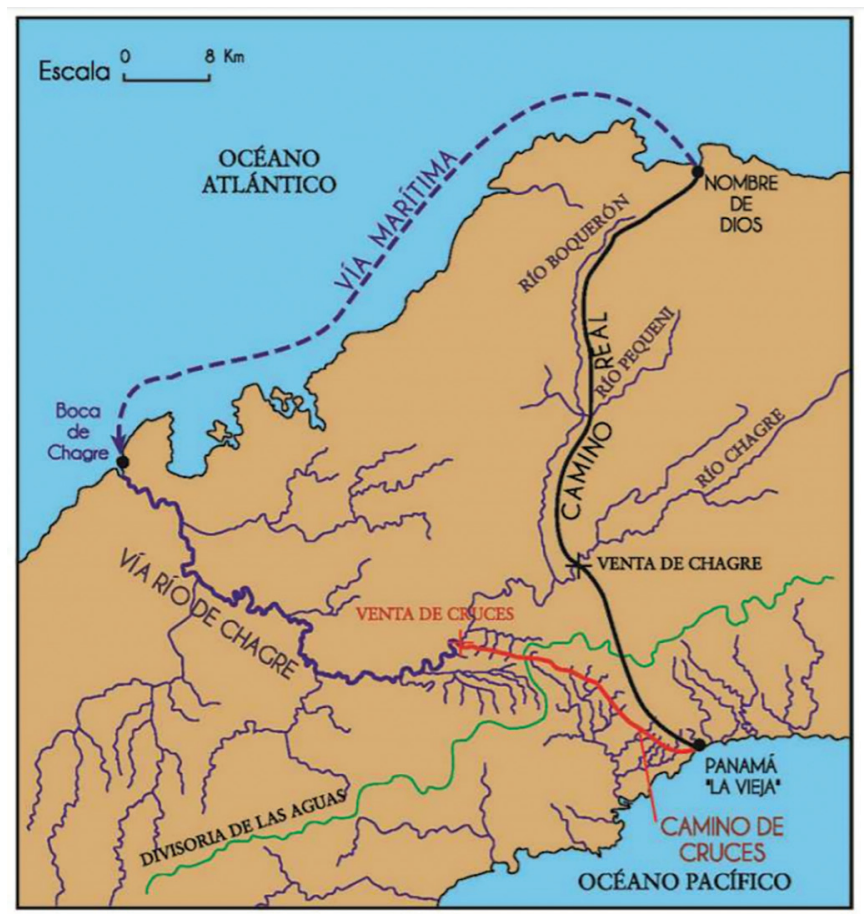

Fuente: Estrella Figueras Vallés, "El cruce del Istmo centroamericano: un proyecto renacentista", en América: Poder, Conflicto y Política. Universidad de Murcia, 2013.

una sola ruta y por lo tanto un monopolio sobre la interoceanidad del istmo.

Al presentar algunos elementos de la vida en la ciudad de Panamá colonial y su relación con el río Grande, se intentará describir un paisaje con características ambientales e hidrológicas que eran el resultado de relaciones sociales particulares, determinadas tanto por el transitismo y su trata de esclavos como por el entorno tropical. En la época seca, cuando los ríos del Pacifico se secaban, el trabajo de los aguateros y las bestias de carga virtualmente conectaba el río Chagres con la cuenca del Grande, asegurando el abastecimiento de la ciudad y los poblados aledaños ${ }^{6}$. Como todos los paisajes culturales, eran el resultado de flujos materiales del pasado, y la cuenca del río Grande se asemejaba a otras áreas de campiña de un hinterland urbano dominado por el ganado vacuno y porcino, las aves de corral, el arroz, los cítricos y la caña de azúcar.

La descripción más antigua que nos queda del río sigue siendo la de Diego Ruiz de Campo, explorador de la

\footnotetext{
6. El trabajo y contexto de los aguateros en México, cuyo caso tiene gran relevancia para la región en su totalidad, son tratados a profundidad en un dossier anterior, "La organización social del abastecimiento urbano de agua: los aguadores." Ver por ejemplo, Alfaro-Rodríguez, 2017.
} 
primera mitad del siglo XVII, quien describió el hinterland de Panamá la Vieja de la siguiente manera:

\begin{abstract}
"Un quarto de legua desde dicho [cerro] Ancon para la parte del Oeste está una ensenada que tiene playas por una y otra banda i tiene toda ella un tercio de legua de ancho, la cual dicha ensenada está toda abierta al Sur i al medio de ella sale la boca del río Grande i coge toda la dicha distancia i á la entrada deste dicho río está una isleta llana toda llena de manglares sin que haya arbol de provecho i la dicha isleta es anegadiza, i causa tener el dicho rio dos canales en la boca i la de mano derecha es mas fondable que pueden entrar i entran por ella barcos i suben con la marea mas de dos leguas el rio arriba á cargar cal, miel, maíz, plátanos i otras cosas que hai arriba en el dicho rio, todo el qual de una y otra banda esta cubierto de arboleda de manglares mui altos que no son de provecho para cosa alguna [...]"7.
\end{abstract}

La cuenca baja del río Grande, con su estuario expuesto a las mareas de la Bahía de Panamá, cumplía una función estratégica en la transportación de alimentos producidos en las cercanías de la ciudad de Panamá, un elemento fundamental para la continuidad del engranaje que permitía el funcionamiento de la ruta transístmica colonial y de la primera mitad del siglo XIX. La oligarquía terrateniente asentada en la que fue la capital de la Real Audiencia de Panamá y pequeños productores aprovechaban en su totalidad las características del ganado criollo, el animal dominante de los asentamientos oficiales, cuya población istmeña pasaría a formar la base genética del ganado vacuno de Centroamérica y Suramérica ${ }^{8}$. Como detalla el historiador Castillero Calvo, "Durante el periodo colonial, un mismo vecino que habitaba en la capital y que se dedicaba al comercio, o tenía casas de alquiler, recuas de mula o chatas para navegar el Chagres también era dueño de ganado e invertía en la minería"9

La cuenca histórica del río Grande, que abarcó aproximadamente 85 millas cuadradas, podría alojar unas trescientas fincas. Una reconstrucción de la cuenca histórica arrojó un área de 167.83 kilómetros cuadrados o 16.783 hectáreas, y un perímetro de 65 kilómetros. La cuenca exhibía una configuración dendrítica (en forma de árbol) con drenaje "anastomasado." Este tipo de drenaje "caracteriza a las llanuras de inundación donde los meandros de la corriente principal dan lugar a ciéna-

\footnotetext{
7. Jaén Suárez, 1986, 53.

8. Castro Herrera, 2008, 21

9. Castillero Calvo, 2013.
}

gas, a fangales, a meandros fósiles y a canales entrelazados"10. La corriente principal, el río Grande, generaba depósitos aluviales, dando lugar a una agricultura fértil en sus riberas medias y bajas.

Tradicionalmente, las tierras bajas ribereñas fueron habitadas por grupos que trabajan rozas anuales de maíz, molinos de azúcar y la cría de ganado bovino y porcino. Los excedentes de sus tipos de pluviagricultura se llevaban río abajo a bordo de canoas para ser vendidos en la ciudad de Panamá. Durante la temporada de lluvias, los ríos de la cuenca del Pacífico retardaban los viajes por tierra al interrumpir las sabanas a lo largo de la costa, dificultando la conexión de la ciudad con sus hinterlands laterales y encareciendo la importancia del río Grande. En la estación seca, los caudales de los ríos de esta vertiente se reducían a goteos, dejándolos generalmente innavegables. A pesar de la gran variabilidad estacional del río Grande, cualidad que compartía con los ríos del área que drenan hacía el sur, este se insertaba dentro de un sistema socioecológico de la ciudad de Panamá, y su rol se acentuaba debido al paisaje físico de la vertiente y la concentración demográfica en una ciudad con poca vocación agropecuaria.

Durante la era preindustrial del corredor interoceánico, el primer periodo de este análisis, el régimen de uso de recursos generaba desigualdades entre grupos sociales. La impronta ambiental de esta etapa del corredor, cabe agregar, obedecía la reducida escala de su infraestructura correspondiente, y a la escasa población del istmo. A pesar de constantes fluctuaciones en el volumen y valor de las mercancías y otros flujos, durante el periodo colonial, la población nunca superó los 1500 habitantes, quienes dependían principalmente de la agricultura y el transporte de pasajeros y de carga a lomo de mula ${ }^{11}$. La huella ecológica de la ciudad de Panamá en los tiempos de la tecnología de mulas e infraestructura de caminos de piedra no demostró ser insustentable. Sin embargo, el ordenamiento territorial del istmo llevó a la consolidación de un único corredor interoceánico cuyos beneficios eran monopolizados por una capa social particular, una forma de organización socioeconómica que Castillero Calvo ha denominado como transitista ${ }^{12}$, y que aún hoy genera desbalances en diversas escalas.

\footnotetext{
10. Camaño y Quintero, 2017, 83.

11. Heckadon Moreno, 1993, 132-133.

12. Castillero Calvo, 1974. Para una aplicación del término a la historia ambiental, ver Castro Herrera, 2008.
} 


\section{La era industrial del corredor interoceánico}

A partir de finales del siglo XVIII, un mercado mundial en expansión posibilitó la mecanización de la producción, el transporte y la comunicación en el Viejo Mundo. El aprovechamiento de nuevas fuentes de energía aumentó la rentabilidad de las empresas capitalistas, especialmente en los países del Atlántico Norte. No fue hasta el siglo XIX que las tecnologías nuevas y el capital acumulado en la producción industrial retroalimentó rápidos avances en el transporte dependiente de combustibles fósiles ${ }^{13}$. Esta revolución, encabezada por el ferrocarril pero que incluía una miríada de máquinas a vapor, generó una explosión en la destrucción creativa de la economía a nivel mundial, articulada a una aceleración violenta en el metabolismo global. La acumulación sin precedentes y el crecimiento de la población, características del capitalismo industrial emergente, se aunaron a esta desigual mecanización de la producción, a diversas escalas, para exacerbar la ruptura planetaria entre campiña y urbe, un aspecto principal de la crisis ecológica mundial. En el istmo de Panamá, un claro ejemplo de esta ruptura ocurrió en la cuenca del río Grande y la ciudad de Panamá.

Nuevas fuentes de energía y técnicas productivas, como el procedimiento Bessemer para la fabricación de acero, marcaron el desarrollo de nuevos tipos de relaciones de producción y la mercantilización del capital natural. En esta coyuntura, las condiciones de la ecología-mundo y la carrera imperial por los recursos naturales determinaron un cambio paradigmático en las relaciones humanas con la naturaleza no humana. Estas actitudes antropocéntricas se volvieron dominantes en las metrópolis imperiales, y se reprodujeron entre elites criollas, aunque siempre condicionadas por narrativas y factores locales. El capital industrial solo valoraba el potencial comercial de elementos específicos de los ecosistemas, una visión del mundo que redujo la naturaleza ambiental a su momento productivo, mirándola como una reserva de posibles mercancías.

La experiencia de Panamá en la era de las independencias latinoamericanas fue problemática debido al retardado desarrollo de las fuerzas productivas existente en el istmo, un resultado del declive en el tráfico interoceánico durante las Reformas Borbónicas. Durante las primeras décadas del siglo XIX, las elites urbanas,

\footnotetext{
13. Bunker, 2007, 239.
}

o la ciudad letrada, se dedicaron a abogar por leyes en Bogotá que potenciaran las ventajas de comercio de la provincia colombiana. La clase dominante blanca de Panamá formuló un nuevo plan para el futuro: un "proyecto hanseático". Como afirma el historiador norteamericano Aims Mcguiness, durante la primera mitad del siglo XIX, el término comunicación era usado regularmente por pensadores de la elite en Panamá para denotar específicamente la circulación de mercancías, personas e información de un punto del planeta a otro. Para estos autores, por consiguiente, el concepto de "soberanía" denotaba principalmente la organización y la proyección de poder sobre el territorio y los flujos de personas, información y bienes a través de medios gubernamentales y extra-gubernamentales ${ }^{14}$. La oligarquía, con algunas excepciones, se aferró a un ideario que no dejaba espacio para el desarrollo de fuerzas productivas que no estuviesen directamente relacionadas con su concepto de comunicación como producción, concebida como la mejor forma de aprovechar la vocación geográfica del istmo.

La realización de esta visión significó la perpetuación de la dependencia del tránsito internacional de flujos a través del corredor interoceánico. Esta ideología se manifestaba en un discurso que establecía que el tránsito era la única forma de resolver satisfactoriamente la dialéctica entre la civilización y la barbarie en el istmo. Los proponentes del proyecto hanseático veían la interacción con extranjeros blancos como legitimadora de su proyecto de nación. Aunque por necesidad se respetase los dictámenes de Colombia, la intención globalizante de la élite urbana tradicional buscaba consolidar a Panamá como un "emporio del comercio universal". El llamado movimiento hanseatista proponía que Panamá, al igual que los puertos de la liga hanseática que una vez dominó el comercio marítimo del Báltico, debiese gozar de un estatus especial como una zona de libre comercio: con autónoma gestión de sus propios asuntos, pero protegido por una o más grandes potencias navales ${ }^{15}$. Mariano Arosemena, por ejemplo, anticipa la entrada del corredor interoceánico a la era industrial dentro de esta forma de concebir los flujos y aprovechar la posición geográfica de Panamá. En 1824, el escritor y hombre de negocios delimita el espacio geográfico que ocuparía su corredor ideal: especifica que sería una vía fluvial, buscando desacreditar rumores acerca de un posible ferrocarril, que atravesaría

\footnotetext{
14. McGuiness, 2008, 9.

15. McGuiness, 2008, 85- 86 .
} 
la región histórica constituida por el río Chagres y río Grande $^{16}$. El fracaso de las clases capitalistas de Colombia de reunir el capital para financiar la industrialización del corredor interoceánico autónomamente tuvo consecuencias catastróficas para la historia de Panamá, ya que las condiciones geopolíticas pondrían al istmo en el ojo del imperio yanqui. Al decir del geógrafo panameño Omar Jaén Suárez, "Panamá dejaría de ser el istmo de Sevilla, Cádiz, o incluso Jamaica, ya que los poderes noratlánticos desplazarían estos antiguos centros de poder. "Panamá se convertiría en el istmo de Nueva York"17.

Hasta entrado el siglo XIX, la organización del trabajo en la región de tránsito en Panamá mayormente obedeció la lógica de la oligarquía española y luego colombiana, que veía en la naturaleza del istmo fuente inagotable de enriquecimiento personal y estatal aunque no se empeñara en desarrollar los productos de la agricultura tropical en boga como el azúcar. Algunas culturas occidentales habían desarrollado nuevas técnicas hidráulicas, pero las condiciones aún no eran propicias para iniciar un proyecto canalero cuando se dio un hecho inédito en suelo norteamericano, en un territorio recientemente arrebatado a México. El descubrimiento de oro en California en 1848 creó un factor de atracción para personas y capitales de diversos orígenes. En el imaginario espacial estadounidense, varias rutas a través de América Central comenzaron a figurar como posibles para llegar a la costa occidental de los EE.UU desde los Estados del Este. La ruta de Panamá se presentó más asequible que la de Nicaragua para la construcción de un enlace ferroviario de pasajeros marítimos. La ruta tormentosa que unía las costas estadounidenses por tierra, cruzando las extensas planicies del West estadounidense, llevó a buscar alternativas para cruzar entre costas.

Panamá era la opción más segura y más conveniente, aunque la construcción del primer ferrocarril tropical se perfilaba como un hito de la ingeniería. La línea del ferrocarril, financiada por el capitalista norteamericano Henry Aspinwall, comprendía la misma ruta que los caminos coloniales, aprovechando el valle de los ríos Grande y Chagres en un país topográficamente fractura$\mathrm{do}^{18}$. La construcción de una vía férrea conllevó efectos ambientales negativos como la deforestación y el relleno generalizado de humedales. La construcción de un

\footnotetext{
16. Arosemena, 1999 (1840), 132.

17. Jaén Suárez, 1998, 274.

18. Esta cercanía de la línea del ferrocarril al curso del cauce del río Grande se aprecia con claridad en el Mapa 4, una de las ilustraciones contemporáneas mas difundidas del ferrocarril transístmico de Panamá.
}

Mapa 4. El Ferrocarril de Panamá (1861)

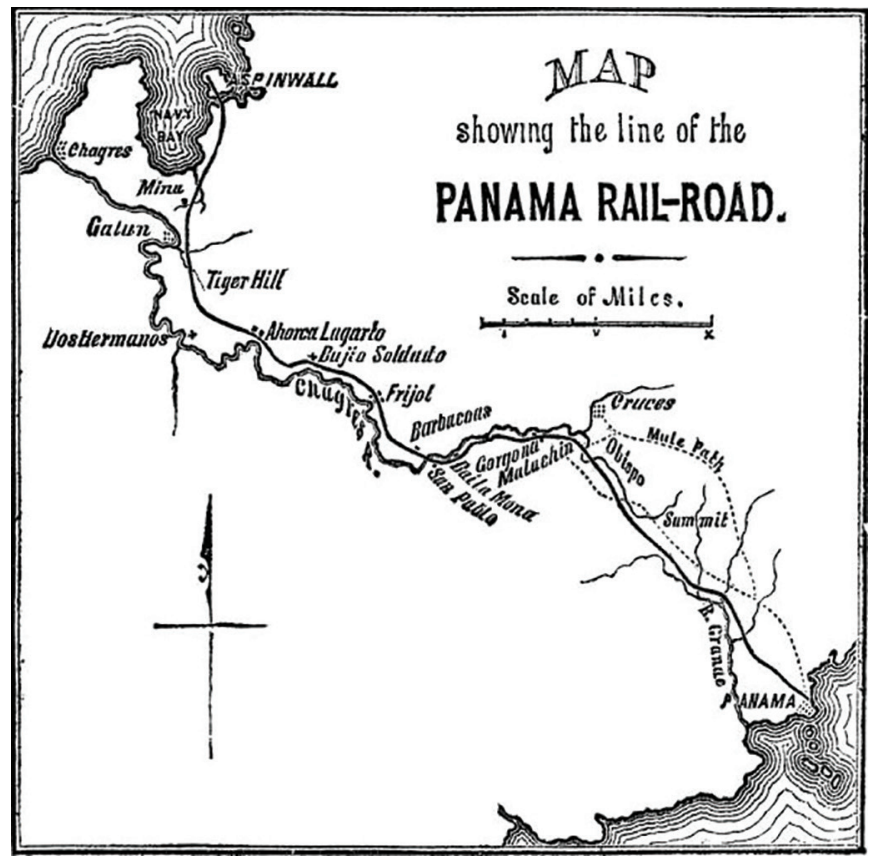

Fuente: Fessenden Nott Otis, Illustrated History of the Panama Railroad (Harper \& Brothers: New York, 1861).

nuevo puerto en el Caribe alineó al río Grande y la ciudad de Panamá con la nueva terminal en el Atlántico del corredor interoceánico, la ciudad de Colón. Es más, para atravesar la pendiente del Pacífico con mayor facilidad, la ruta descendía por las riberas del río Grande, cruzando algunos de sus afluentes en varias ocasiones. Más allá de la importancia para la historia de la migración interna de EE.UU., la ruta ferroviaria potenció el comercio entre países latinoamericanos, siendo explotada con regularidad por los países de América del Sur para abaratar sus costos de envío a Europa y el Caribe.

La posición de Panamá dentro del imaginario geográfico de EE.UU., y las actitudes racistas que posteriormente se derivarían del racismo científico y el determinismo ambiental, prefiguró la imagen del istmo en el imaginario colectivo del máximo poder regional entonces ${ }^{19}$, y posteriormente mundial. La coexistencia de estadounidenses y panameños en Panamá durante este periodo fue uno de los primeros encuentros de la sociedad norteamericana y la América tropical. El intento de construcción de un canal por capitalistas franceses también se ubicó en el centro del istmo, naturalizando aún más la organización del espacio istmeño en su modalidad transitista. De esta manera, estos proyectos ubicados en el mismo espacio perpetuaron la organización transitista del tránsito, y el carácter monopólico de sus beneficios. La concentración geográfica del único en-

\footnotetext{
19. Frenkel, 1996, 317.
} 
clave de la economía panameña que estaba insertada en la ecología-mundo relegó al resto del territorio, lo que hoy denominamos el interior del país, a una posición de proveedores de subsidios económicos y ambientales para sostener esta actividad económica y su hegemonía sobre el modo de producción.

Durante la segunda mitad del siglo XIX, el creciente poder del capital transnacional empieza a transformar paisajes del neotrópico. En 1869, el mismo en que el Canal de Suez empezó a comunicar el mar Rojo y el Mediterráneo a través del desierto egipcio, en la ciudad de México se pondría en marcha la construcción del anhelado Gran Canal, que resolvería el problema de las aguas residuales. Los proyectos hidráulicos del Porfiriato son ejemplos de un fenómeno regional mayor y de sus connotaciones autoritarias durante la época del liberalismo económico. La realización de proyectos estatistas de grandes dimensiones por parte de los gobiernos regionales permitió dominar la naturaleza, empleando nuevas tecnologías como excavadoras y dragas masivas. El historiador mexicano Luis Aboites Aguilar llama a la década de los años 1880 "la gran hidráulica", una etapa en la cual los recursos hídricos se explotarían como condición para el florecimiento de la inversión extranjera directa en América Latina ${ }^{20}$.

La llamada segunda revolución industrial tendría consecuencias mayores para los paisajes del Panamá central. Las tecnologías desarrolladas en el centro del sistema mundo obedecían a una cultura de la naturaleza que correspondía a sus ecosistemas, y su técnica hidráulica se intensificó en sus impactos ambientales por cambios paradigmáticos en la ciencia y su filosofía. Las culturas humanas finalmente tuvieron la capacidad para detener casi cualquier río. El uso estructural del hormigón se convirtió en una práctica bien establecida en la ingeniería occidental, a un grado no visto desde los tiempos de los romanos. Por toda la cuenca del Caribe, durante el período inicial de la formación de una clase trabajadora, el capital extranjero se dirigía con intensidad hacia grandes proyectos de infraestructura extractiva, explotando fronteras de mercantilización que yacían ajenas al capital regional, con tendencia agropecuaria. Similar al caso del ferrocarril a mediados de siglo, el desarrollo de una mentalidad transitista entre la elite local y las condiciones históricas que operaban dentro de los EE.UU. ayudan a identificar los agentes de cambio ambiental a principios del siglo XX de Panamá.

20. Aboites Aguilar, 1999.

\section{El Canal de Panamá}

Durante las primeras décadas del siglo XX, los estados del Noratlántico llegaron a controlar una abrumadora cantidad del espacio mundial. En el caso de EE.UU., el cierre de su famosa "frontera" interna representó una barrera espacial para la acumulación de capital ininterrumpida, que llevó a su clase dominante a mirar más allá de su territorio contiguo. La creciente presencia de productos tropicales, con anterioridad exóticos y caros, en mercados norteamericanos simbolizó la creciente hegemonía de EE.UU. en Asia tropical y América Latina. Sin embargo, una visión estrictamente mercantilista del impulso imperialista de EE.UU. no termina de explicar las políticas del país en la región que había aprendido a ver como su patio trasero desde la época de la doctrina Monroe. Este sentimiento de recelo se vería revigorizado en los tiempos del corolario de Roosevelt.

La expansión exterior de los EE.UU. también fue producto de la agitación de intelectuales y las acciones de políticos que sistematizaron un sentimiento, hegemónico entre las clases capitalistas, que catalogaba la búsqueda de paz como aislacionismo. Un pensador que incidió en el cambio ambiental en Panamá, aparte del mismo Theodore Roosevelt, fue el capitán Alfred Mahan (1849-1914). Mahan articuló su visión socio-militar en un estudio de 1890 titulado "La Influencia del Poder Naval en la Historia"21, que promovía la participación de EE.UU. en la carrera armamentística naval mundial. Un impulso mercantilista, aunado al deseo de proyectar mayor poder militar, trajo incómodos temas de coloniaje e imperialismo a la mesa de debate de la democracia yanqui. Al mismo tiempo, la manipulación de un número creciente de elementos del paisaje y la gestión ambiental pasaron a ser piezas fundamentales de un nuevo estado liberal estadounidense, que surge en respuesta a problemas sociales ${ }^{22}$.

Nuevos avances en la tecnología, la medicina y en las herramientas para la construcción de un estado-nación causaron cambios cualitativos en la relación entre la gestión ambiental estadounidense y la construcción de un nuevo imperio. La América tropical, y sus habitantes, estaban predestinados al abuso en este proyecto colonial debido a la jerarquización ambiental y racial existente en un EE.UU. que apenas salía de su provincialismo tradicional. La cultura de la naturaleza dominante en Norte América depositaba su confianza plena en la ciencia contemporá-

\footnotetext{
21. Mahan, 1890.

22. Una aproximación a este proceso estrictamente estadounidense y desde una perspectiva regional, en Ring, 2012.
} 
nea, y se afianzaba en la modificación de paisajes y sobre la ideología del Darwinismo Social ${ }^{23}$. A medida que avanzó el siglo XIX, la yuxtaposición geográfica y cultural entre los EE.UU. y el mundo tropical hicieron de los trópicos, al decir de Paul Sutter, "el medio ambiente dominante en el imaginario de la expansión extracontinental de EE.UU., tanto como el wilderness lo era para la continental" 24 .

En este contexto de una cambiante cultura material de la sociedad occidental, se desarrolló un conflicto de ecología-política entre las elites de Panamá y Colombia por el control sobre la preciada ruta interoceánica. Esta disputa interna fue resuelta a la fuerza por los EE.UU., que intervino en las postrimerías de la Guerra de los Mil Días para apoyar a las fuerzas independentistas, mayormente oligárquicas, del istmo. En 1902, la victoria Conservadora en esta última guerra civil decimonónica en Colombia trajo consecuencias devastadoras para los sectores populares en Panamá especialmente en los conflictos pertinentes al uso de los recursos naturales que se desarrollaban en el istmo. Teddy Roosevelt procuró tomar medidas drásticas para hacer prevalecer su voluntad de construir un canal en Panamá contra la opinión de Bogotá. Para lograrlo, Roosevelt apeló al espíritu de la reciente enmienda Platt, y procedió a apropiarse del espacio necesario para la ruta canalera. El poder ejecutivo, liderado por Theodore Roosevelt, se adjudicó más poder unilateral sobre decisiones de política exterior que en todo el decimonono estadounidense, apoyó una rebelión en la provincia panameña, rompiendo así los vínculos jurídicos entre Bogotá y Panamá, y estableciendo un Estado nominalmente independiente. El resultado fue la creación de una de las repúblicas bananeras que predominaron en la región a principios del siglo XX, y que permaneció en estado de protectorado hasta la década de los treinta del siglo pasado. El tratado Hay-Bunau Varilla de 1903 garantizó los derechos necesarios para que Washington pudiese construir un canal y además establecer una Zona del Canal. A diferencia del intento francés por construir un canal a nivel del mar, el proyecto norteamericano tuvo intención colonialista y militar desde el comienzo, lo cual se explica por el respaldo del estado liberal progresista y crecientemente presidencialista de EE.UU.

La valoración del mundo no humano dentro de la cultura de la naturaleza en EE.UU. se incrustó en la orientación y filosofía de su ciencia, incluyendo su geopolítica. La lógica de la construcción de bases militares fuera

\footnotetext{
23. Peet, 1985.

24. Sutter, 2007, 727.
}

de sus límites nacionales se vio revigorizada en la era de la guerra industrializada. Estas bases formaron parte intrínseca del proyecto neo-colonial: la Comisión del Canal Interoceánico, a diferencia de los ingenieros franceses que los precedieron, abogaron por una vía interoceánica que incluyera la adquisición de los derechos a los terrenos colindantes ${ }^{25}$. Este imperativo se manifestó en el uso de la tierra en la cuenca del río Grande, que llegó a albergar nueve bases militares estadounidenses distintas ${ }^{26}$. Las formas aplicadas de la ciencia -como la ingeniería civil, mecánica de fluidos y la hidráulica-alcanzaron alturas inéditas dentro de este paradigma reduccionista. A través de la hidráulica del decimonono tardío norteamericano, estos nuevos modos de valorización de la naturaleza no-humana llegarían a incorporar pragmáticamente el paisaje a su proyecto de nación

Si bien al principio del proyecto la intención de la Comisión del Canal Interoceánico era construir un canal a nivel del mar como lo intentaron los franceses pero con mano de obra europea, el proyecto mutó en un canal a esclusas construido mayormente por barbadenses. Campesinos antillanos sin tierra proporcionaron una reserva laboral que satisfizo la mayor parte de los trabajadores manuales que en última instancia construyeron el canal. Este cambio reflejaba la internalización de los obstáculos de la naturaleza del istmo, y encontró la solución en esta misma naturaleza. La abundancia de agua creó una nueva dependencia de lagos artificiales navegables y de nuevos reservorios de agua dulce para el consumo humano y los esclusajes. En este sentido, la decisión de la C.C.I. de construir un canal a esclusas entrelazó la historia del agua urbana en la región con la del Canal de Panamá, la más reciente forma del corredor interoceánico. Guillermo Castro Herrera sostiene que, para el grupo social que impulsó el canal, el elemento más sobresaliente del orden natural era la coincidencia de una serie de circunstancias biofísicas- como la ubicación geográfica, topografía, clima, y la hidrografía. Las lecciones del fracaso francés y el enfoque pragmático estadounidense permitieron a la técnica hidráulica proveer una solución tecnológica capaz de convertir en ventajas lo que hasta ahora habían sido obstáculos paralizantes para la materialización de una vía acuática: el régimen de fuertes lluvias y la topografía complicada. Sin embargo, estas nuevas técnicas y conocimientos no hubiesen servido para controlar la naturaleza de los ríos Chagres y Grande si no fuese por la participación del

\footnotetext{
25. Lasso, 2015.

26. Las nueve bases eran: Fuerte Clayton, Howard, Kobbe, Rodman, Cocoli, Corozal, Albrook, Curundu y Quarry Heights.
} 
estado y el capital norteamericano, y la reserva laboral que se encontraba en la región del Caribe.

La gestión ambiental y epidemiológica de los EE.UU. en el istmo, especialmente algunas de sus intervenciones en los ecosistemas, tendrían consecuencias inesperadas que atentaron contra los intereses imperiales en el istmo. Sutter estudió las medidas adoptadas por la C.C.I. en su campaña de saneamiento para erradicar los vectores de las mortales fiebres. Aunque estas enfermedades eran endémicas en la región, los avances en el dragado de un canal a esclusas creaban condiciones que favorecían a los mosquitos, y estas condiciones no se debían a la naturaleza tropical en sí, sino a las perturbaciones ambientales causadas por la C.C.I. Las consecuencias inmediatas de los cambios en el paisaje resultaban catastróficas, ya que los mosquitos se reproducían en charcos de agua estancada en espacios de la obra libres de vegetación. Aceptar este hecho, observa Sutter, no encajaba bien con la ideología tecnócrata fundamentada en el triunfo del hombre blanco sobre la naturaleza virgen del trópico, y justificada por una creencia en la perfectibilidad de la sociedad a través de la tecnología. Algunos de los mejores ejemplos que utiliza Sutter para demostrar esta contradicción en las prácticas de gestión ambiental provienen de las perturbaciones hidrológicas efectuadas en la cuenca del río Grande $^{27}$. No obstante, la articulación entre los cambios del río Grande y las transformaciones urbanas que coincidieron con ese proceso en la ciudad de Panamá no ha sido explorada. Una aproximación a esta interrogante, desde el enfoque del uso del agua, ocupará el resto de este artículo.

La devastación de la cuenca del río Grande se consuma bajo el liderazgo del proyecto canalero del ingeniero de ferrocarril, John Frank Stevens, quien priorizó la construcción de infraestructura para las poblaciones civiles y militares de la Zona del Canal, e inclusive paraliza las excavaciones con este fin. Una vez los trabajadores blancos del canal habían sido acomodados con respecto a sus condiciones materiales, Stevens transformó el proyecto a través de un enfoque de ingeniería ferroviaria, que convirtió al ferrocarril en la principal herramienta de la operación. Un sistema de carriles móviles despachó la tierra de la excavación y los escombros de las explosiones sin importar en qué punto de la línea se encontraran las excavaciones. Esta tecnología aumentó la eficacia de las excavadoras a vapor Bucyrus, ya que los deslizamientos y las fuertes lluvias creaban la necesidad de crear vertederos fuera de la hoya hidrográfica,

\footnotetext{
27. Sutter, 2007.
}

que pudieran absorber grandes cantidades de tierra. Estos rellenos, o dumps, conllevan un impacto ambiental significativo, especialmente en áreas de humedales tropicales. Algunos de los vertederos más grandes creados por la C.C.I. fueron Tabernilla y Gatun en la vertiente Caribeña, y La Boca y Miraflores, ubicados en la cuenca media y baja del río Grande respectivamente. La clave para lograrlo sería el sistema ferroviario empleado para funcionar como una banda transportadora, una cinta que desplazaba el desecho a los lugares donde servirían los intereses imperiales de Estados Unidos: los vertederos, calzadas, presas de tierra, y manglares malsanos.

La vía acuática que justificaría el establecimiento de una colonia formal consistió en un canal mecanizado con tres juegos de esclusas, tres represas grandes, una serie de embalses, y una red de estaciones hidrográficas que obtendrían las mediciones de la precipitación y los cambios fluviales y lacustres relevantes. La sección del Pacífico, que ocuparía en gran parte el valle y curso del río Grande contaría con dos juegos de esclusas debido a la naturaleza de la pendiente, las esclusas de Miraflores y Pedro Miguel ${ }^{28}$. En esta vertiente, como en el resto de la ruta, se edificaron asentamientos temporales y permanentes, y estos estaban segregados racialmente mediante una diferenciación de la planilla laboral: a los blancos se les pagaba en oro y a los no blancos en plata, la moneda local. Esta urbanización transformó paisajes de sabana, bosques tropicales lluviosos y secos, y humedales de diversos tipos, en paisajes culturales que seguían una lógica dedicada al funcionamiento del canal a través de la concentración de la población y la mano de obra.

A lo largo de sus cuencas media y baja, el valle del río Grande había sido utilizado históricamente para el ganado y luego, con menor intensidad, para la agricultura tropical de exportación. La ética ambiental de los tecnócratas estadounidenses estableció un régimen diferente del uso del suelo y el agua, encarnado por ejemplo en una gestión radicalmente diferente de los humedales y manglares. Las representaciones de pantanos peligrosos, cuya vegetación emanaba miasmas mortales, había dejado una huella profunda en el imaginario ambiental estadounidense. La nube de sospecha que gravitaba sobre estos ecosistemas no subsistió ni gracias a la aceptación lograda por la teoría microbiana en la comunidad científica transnacional. La teoría del mosquito como vector alimentó nuevas preocupaciones acerca de la salubridad

\footnotetext{
28. En el mapa 5, las esclusas de Miraflores y Pedro Miguel están denominadas como Miraflores y Pedro Miguel "locks," la traducción de esclusas al inglés. El río Pedro Miguel, incorporado al funcionamiento de su esclusa epónima, desembocaba originalmente en el curso principal del río Grande.
} 


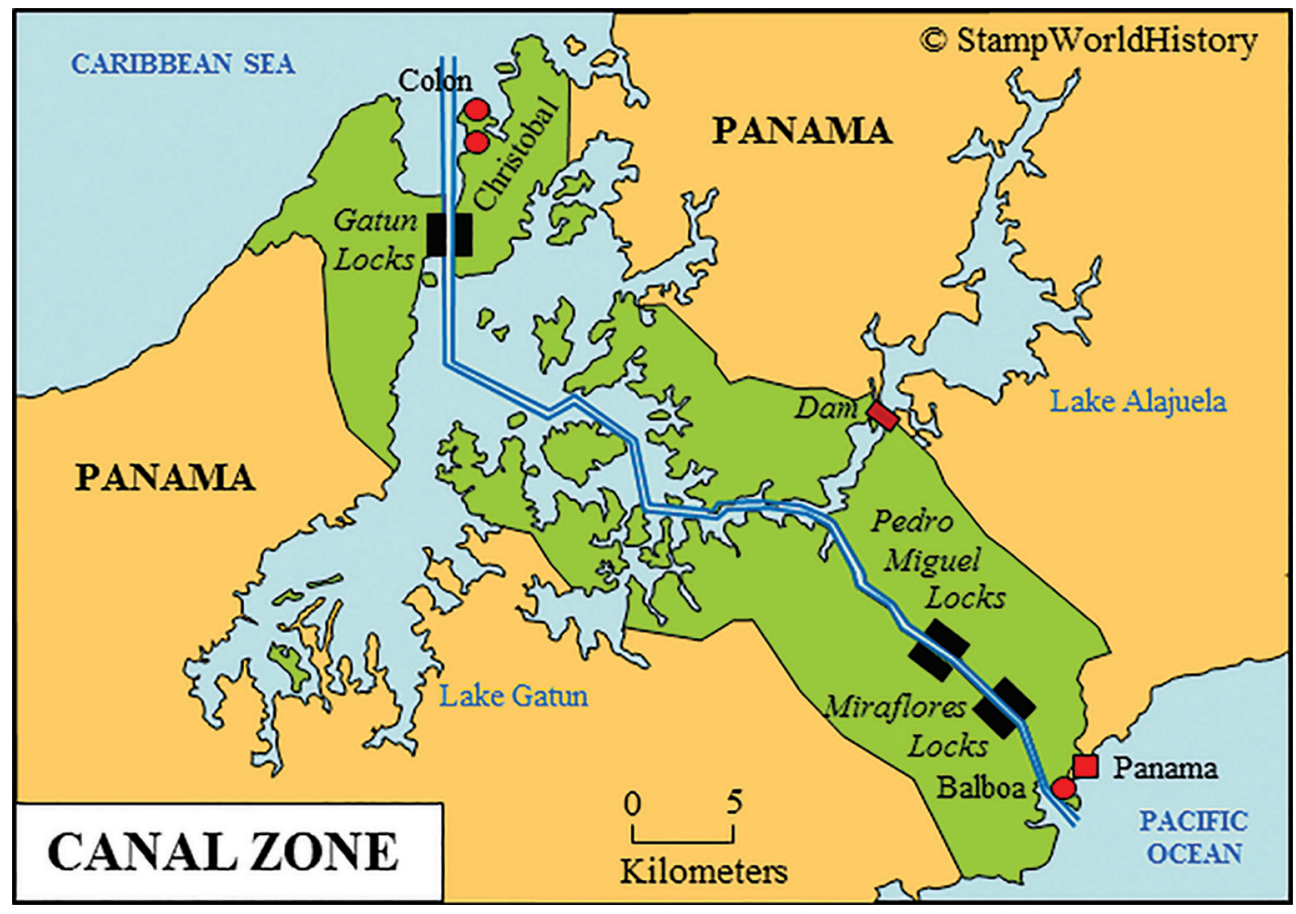

Fuente: Sitio web difunto StampWorld.com. Disponible en http://bigblue1840-1940.blogspot.com/.

de los pantanos, donde proliferaban estos vectores de enfermedades tropicales, reforzando la asociación de los humedales con la pestilencia y así facilitando su relleno. A partir de 1913, los EE.UU. recurrieron a despoblar la ruta interoceánica de su población original, mayoritariamente negra, que había sido el núcleo poblacional de Panamá hasta entonces ${ }^{29}$. Para lograrlo, oficiales de la CCI naturalizaron la inferioridad de los panameños residentes en estas áreas en el imaginario colectivo, utilizando medios como las representaciones cartográficas y discursivas para degradar a estos grupos, otrora autónomos al decir de Lasso, "de ciudadanos a nativos." Aunque se realizaron estudios en la Zona del Canal para evaluar su potencial agrícola, actitudes racistas y militaristas llevaron a la expulsión de todos los panameños de la Zona del Canal $^{30}$. Este proceso de despoblamiento transformó el valle del río Grande.

Estos cambios demográficos se afianzaron sobre un cambio en el ciclo hidrológico de la región, que terminaría afectando la relación social con los recursos hídricos. El reporte de los ingenieros del Canal al Congreso en 1906 señala que algunos ríos deberían ser aislados de sus cuencas por represas, y otros serían absorbidos por el canal. Los ríos, que en última instancia se redirigirían hacia el canal, sin embargo, también deberían ser des-

\footnotetext{
29. Lasso, 2019.

30. Carse et al., 2016.
}

viados temporalmente hacía el mar durante las excavaciones; en el caso del río Grande esto implicó un túnel de más de un kilómetro de largo para drenar algunos de sus afluentes. La transformación del paisaje hídrico alcanzó una escala mayor durante la tercera etapa de la construcción (1907-1914), bajo la dirección militar del ingeniero civil George Goethals. Para los ingenieros estadounidenses, prevenir que las descargas de sedimento del río Grande alcanzaran el Pacífico, para entonces subsumir su valle al nuevo canal, fue una tarea de primer orden, casi tanto como controlar el violento río Chagres. El resto de esta sección explicará cómo los paisajes hídricos del valle en cuestión sufrieron transformaciones radicales durante la construcción del canal y las primeras décadas de su operación, período que presenció la reorganización del sistema fluvial de la cuenca del río Grande, desde su cuenca alta y media hasta la desembocadura en la Bahía de Panamá, cerca del área hoy llamada La Boca.

Al sur de la confluencia del río Grande con el río Pedro Miguel, el río Grande entraba en su cuenca media, donde sus meandros comenzaban a formar fértiles vegas aluviales. En algunas secciones, el cauce del río se alineaba lo suficiente con los de la línea canalera que la C.C.I. optó por incorporarlo al canal. Las esclusas de Pedro Miguel, las primeras al cruzar la Cordillera hacia el Pacífico, reciben agua del lago Gatún para realizar sus esclusajes. 
En las proximidades del corte Culebra el río Grande empezaba a formar un claro eje con el río Chagres. El valle del río Grande resultó pieza clave en el abaratamiento de la conquista de la naturaleza de la vertiente del Pacífico. El lago creado en el hinterland de la ciudad de Panamá, el lago Miraflores, era el resultado de la construcción de una represa entre dos juegos de esclusas. La desviación del curso del río en la cuenca media, en las cercanías de la zona hoy ocupada por las esclusas de Pedro Miguel y Miraflores más al norte. El ingeniero H. F. Hodges explica que:

"La obstrucción y las presas en Miraflores forman una barrera al cerrar el valle bajo del Río Grande y conservan el nivel intermedio del lago Miraflores .... El lago recibe el flujo del Cocolí, Pedro Miguel, Caimitillo, y Cameron [sic] ríos, todos pequeños arroyos que antes eran afluentes del Río Grande"31.

Desde las esclusas de Miraflores hasta La Boca, justo afuera de la ciudad de Panamá, se excavó un canal que transformaría la relación entre la ciudad y su hinterland. La cuenca baja del río Grande, un área anegadiza y pantanosa, recibiría la mayor parte de los desechos de la excavaciones en la Cordillera Central. El estuario tropical situado en la desembocadura del río interactuaba con los ecosistemas marinos de la bahía. Las actitudes con respecto a los manglares dio lugar a un consenso entre los ingenieros que proponían rellenar estos pantanos como la forma más eficaz de construir una vía de acceso en el Pacifico. Una serie de rellenos, terraplenes, y trabajos de dragado en la costa de la bahía transformó por completo el estuario de la desembocadura del río Bravo. El frustrante curso original del río se ensanchó y se enderezó, de paso sumergiendo "los pantanos mortales del río Grande allende a Panamá"32. En la parte baja del río Grande, el destino primario para los desechos de tierra de las excavaciones era el vertedero que se convertiría en el pueblo de Balboa, el símbolo imperial en el enclave y la capital de la Zona, que hoy es un distrito al oeste de la ciudad de Panamá.

La historia del río Grande se entrelazó con la del Chagres, y esta con la del agua urbana en el corredor interoceánico. Los planes originales del Canal ya incluían disposiciones para encontrar otras fuentes de agua para el canal y la población, pero una larga sequía entre 1929 hasta 1930 aceleró estos planes de asegurar nuevas fuentes de agua almacenable para la vía acuática y la zona metropolitana de la ciudad de Panamá ${ }^{33}$. Cabe agregar que la población en 1905, el segundo año de la construcción, era de 22.000.

\footnotetext{
31. Hodges, 1916, 45.

32. Hodges, 1916, 46.

33. Carse, 2014, 41.
}

Esta empezaría a crecer a partir de la importación de trabajadores para la construcción de la ruta y del despoblamiento de los asentamientos urbanos existentes en la Zona del Canal ${ }^{34}$. En 1922, el presidente Calvin Coolidge autorizó la creación de una segunda represa y embalse en el río Chagres, obstruyendo su afluente conocido como Alajuela en la cuenca alta. El lago Madden, actualmente conocido como lago Alajuela, se llenó en 1936 gracias a la erección de la represa Madden en el río Alajuela. El área de 22 millas cuadradas que ocupa la represa y el lago fueron expropiados a Panamá por EE.UU. según los términos del tratado de 1903. Esta expansión en el área de la Zona del Canal sería precursora de muchas otras transgresiones, no solo de naturaleza territorial, que exacerbaron los conflictos coloniales en el siglo XX en Panamá, dentro del cual la lucha por el abastecimiento de agua de la capital y Colón ha sido un componente poco estudiado.

\section{Conclusiones}

Una vez reorganizadas en la hoy llamada Cuenca del Canal de Panamá, las aguas del río Chagres y del río Grande pasaron a ser entendidas por sus nuevos amos como un mero insumo en un complejo de ingeniería hidráulica que separaba el agua de sus elementos ambientales, salvo de los estrictamente necesarios para el funcionamiento de la nueva escalera acuática. La cuenca del río Grande fue devastada principalmente por un conjunto de represas y muros de contención que transformaron su curso medio en el actual Lago Miraflores. El impacto del pasado en los ecosistemas del enclave-urbano colonial, como el de la terminal sur del Canal de Panamá, han condicionado la relación estructural del canal con el país y la región, pero también ha condicionado la experiencia vivida de los habitantes de un área metropolitana de la ciudad de Panamá que alberga a casi la mitad de la población nacional. Desde la perspectiva de la historia urbana de la ciudad de Panamá, el imperialismo estadunidense conllevó una aceleración en el metabolismo socioambiental, y el valle del río Grande ofrece así un caso presago de como los espacios urbanos y sus paisajes acuáticos se moldearían bajo las relaciones de poder del capitalismo de estado.

Si el río más importante de la capital y ciudad mayor de un país desapareciera en cuestión de meses a mano de un poder extranjero, luego de cientos de años de ocupación y uso, se esperaría que el trauma asociado a tal pérdida fuese empecinado y multigeneracio-

34. Lasso, 2019. 
nal. No obstante, en Panamá un evento de tal magnitud tuvo lugar hace poco más de un siglo, y la memoria de agua de la ciudadanía no tiene lugar para rememorar el río extinto, ni mucho menos imaginárselo en un estado recuperado en los paisajes del mañana ${ }^{35}$. La temporalidad de la historia ambiental profunda permite hacer unas cuantas generalizaciones aunque solo se cuente con un trabajo de archivo limitado, especialmente si la intención es aproximarnos a la tesis de la ruptura metabólica en las relaciones sociedad-naturaleza. La organización pre-industrial del tránsito transístmico, que se remonta al siglo XVI y se caracteriza por ser monopolizada y por concentrarse en la ruta entre los ríos Chagres-Grande, es una característica fundamental de los conflictos y contradicciones que hoy enfrenta Panamá. Sin embargo, en el siglo XXI, la complejidad del sistema socioecológico que sirve de sostén al transitismo oculta los conflictos de ecología política que genera, aunque genere desigualdades comparables a la esclavitud, las encomiendas o la institución de la pureza de sangre que prevalecían durante la colonia.

\section{BIBLIOGRAFÍA}

Acervo del Canal de Panamá (Record Group 185). Archivos Nacionales de Estados Unidos NARA II (Siglas en Inglés). College Park, Maryland, EEUU.

Aboites Aguilar, L. 1999: El agua de la nación. Una historia política de México (1888-1946). Ciudad de México, CIESAS.

Alfaro-Rodríguez, E. 2017: "La red social del abasto urbano: aguadores y fiadores en Zacatecas, México (siglo XIX)". Agua y Territorio, 9, 11-21. https://doi.org/10.17561/at.v0i9.3473

Arosemena, M. 1999: Apuntamientos Históricos (1801-1840). Panamá. Autoridad del Canal de Panamá.

Bunker, S. G. 2007: "Natural Values and the Physical Inevitability of Uneven Development under Capitalism", en Hornborg, A.; McNeill, J. R. \& Martinez-Alier, J. (coords.): Rethinking Environmental History: World-System History and Global Environmental Change, Altamira Press, 239-258.

Camaño J., Luis A., y Daniel Quintero. 2017: "Enfoque Histórico- Geográfico Del Río Grande y Su Legado al Canal de Panamá." Societas, 19 (1), 73-91.

Carse, A. 2014: Beyond the Big Ditch: Politics, Ecology, and Infrastructure at the Panama Canal. Cambridge, Massachusetts. MIT Press. https://doi.org/10.7551/mitpress/9780262028110.001.0001

Carse, A.; Keiner, C.; Henson, P. M.; Lasso, M.; Sutter, P. S.; Raby, M. \& Scott, B. 2016: "Panamá Canal Forum: From the Conquest of Nature to the Construction of New Ecologies". En-

\footnotetext{
35. Los conceptos de memoria e imaginario de agua son examinados por Martos-Núñez y Martos-García, 2015.
}

vironmental History, 21 (2), 206-287. https://doi.org/10.1093/envhis/emv765

Castillero Calvo, A. (Ed.) 2013: Panamá: Historia Contemporánea. Taurus.

Castillero Calvo, A. 1974: "Transitismo y Dependencia: El Caso de Panama". Anuario de Estudios Centroamericanos, 1, 165-186. https://www.jstor.org/stable/25661524

Castro Herrera, G. 2008: "Isthmus in the World: Elements for an Environmental History of Panama". Global Environment, 1, 1055. https://doi.org/10.3197/ge.2008.010102

Castro Herrera, G. 2013: "Panamá, Un territorio en tres tiempos". Historia Ambiental Latinoaméricana y Caribeña, 3 (1), 144-154. https://www.halacsolcha.org/index.php/halac/article/view/172

Frenkel, S. 1996: "Jungle Stories: North American Representations of Tropical Panama". Geographical Review, 86 (3), 317-333. https://doi.org/10.2307/215497

Heckadon Moreno, S. 1993: "Impact of Development on the Panama Canal Environment". Journal of Interamerican Studies and World Affairs, 35 (3), 129-149. https://doi.org/10.2307/165971.

Hodges, H. F. 1916: "General Design of the Locks, Dams and Regulating Works of the Panama Canal," en The Panama Canal II: Design and Erection of Structures, Transactions of the International Engineering Congress. San Francisco, California. Press of the Neal Publishing Company.

Jaén Suárez, 0. 1998: La Población del Istmo de Panamá: Estudio de Geohistoria. Madrid. Ediciones de Cultura Hispánica.

Jaén Suárez, O. 1986: Geografía de Panamá: estudio introductorio y antología. Panamá. Universidad de Panamá.

Lasso, M. 2015: "A Canal without a Zone: Conflicting Representations of the Panama Canal". Journal of Latin American Geography, 14 (3), 157-174. https://doi.org/10.1353/lag.2015.0035

Lasso, M. 2019: Erased: The Untold Story of the Panama Canal. Cambridge, Massachusetts, Harvard University Press. https:// doi.org/10.2307/j.ctvckq61b

Mahan, Alfred Thayer.1890: The Influence of Sea Power Upon History, 1660-1783. Boston, Massachusetts. Little, Brown and Company.

Martos-Núñez, E. y Martos-García, A. 2015: "Memorias e imaginarios del agua: nuevas corrientes y perspectivas". Agua y Territorio, 5, 121-131. https://doi.org/10.17561/at.v0i5.2539

McGuinness, Aims. 2008: Path of Empire: Panama and the California Gold Rush. Ithaca, Nueva York. Cornell University Press.

Peet, R. 1985: "The Social Origins of Environmental Determinism". Annals of the Association of American Geographers, 75 (3), 309333. https://doi.org/10.1111/j.1467-8306.1985.tb00069.x

Ring, N. J. 2012: The Problem South: Region, Empire, and the New Liberal State, 1880-1930. Athens, Georgia, University of Georgia Press.

Sutter, P. 2007: "Nature's Agents or Agents of Empire? Entomological Workers and Environmental Change During the Construction of the Panama Canal". ISIS, 98 (4), 724-754. https://doi. org/10.1086/529265 